Jurnal Neutrino Vol. 3, No. 2, April 2011

\title{
EFEK SUHU PADA PROSES PENGARANGAN TERHADAP NILAI KALOR ARANG TEMPURUNG KELAPA (Coconut Shell Charcoal)
}

\author{
M. Tirono ${ }^{1}$, Ali Sabit ${ }^{2}$
}

\begin{abstract}
Abstrak: Bahan bakar minyak merupakan bahan bakar yang diolah dari sumber daya alam yang tidak dapat diperbaharui. Biomassa merupakan sumber enrgi alternatif terbarukan yang berasal dari tumbuh-tumbuhan dan limbah. Tempurung kelapa dapat diolah menjadi arang yang merupakan bahan baku pembuatan arang briket dengan proses karbonisasi. Temperatur karbonisasi sangat berpengaruh terhadap arang yang dihasilkan sehingga penentuan temperatur yang tepat akan menentukan kualitas arang. Penelitian ini merupakan penentuan nilai kalor dari arang tempurung kelapa dengan suhu pengarangan yang berbeda. Variasi suhu pengarangan yang diberikan yaitu $200^{\circ} \mathrm{C}, 250^{\circ} \mathrm{C}, 300^{\circ} \mathrm{C}$, $350^{\circ} \mathrm{C}, 400^{\circ} \mathrm{C}, 500^{\circ} \mathrm{C}, 550^{\circ} \mathrm{C}$, dengan pengulangan sebanyak tiga kali pada setiap variasi suhu. Penelitian ini bertujuan untuk mengetahui pengaruh suhu pada proses pengarangan terhadap nilai kalor arang. Selain itu mengetahui efisiensi pembuatan arang tempurung kelapa dengan menganalisa perubahan massa bahan sebelum dan sesudah pengarangan. Metode penelitian yang digunakan dalam penelitian ini adalah deskriptif kuantitatif yang ditampilkan dalam bentuk table dan grafik, kemudian data yang dihasilkan dianalisis dengan anova dan regresi linier. Hasil penelitian ini menunjukkan bahwa penyusutan massa dan nilai kalor berbanding lurus dengan tingginya suhu pengarangan. semakin tinggi suhu pengarangan, penyusutan massa bahan semakin tinggi dan nilai kalor semakinbesar.
\end{abstract}

Kata kunci : Pengarangan, Nilai Kalor, Arang Tempurung Kelapa.

\section{PENDAHULUAN}

Bahan bakar minyak merupakan bahan bakar yang diolah dari sumber daya alam yang tidak dapat diperbaharui. Sifat tidak dapat diperbaharui ini akan menyebabkan semakin menipisnya bahan bakar minyak, sehingga perlu untuk memanfaatkan sumber energi alternatif baru yang dapat diperbaharui, ramah lingkungan dan dapat dijangkau oleh masyarakat bawah. Biomassa merupakan sumber enrgi alternatif terbarukan yang berasal dari tumbuh-tumbuhan dan limbah. Tempurung kelapa dapat diolah menjadi arang yang merupakan bahan baku pembuatan arang briket dengan proses karbonisasi. Temperatur karbonisasi sangat berpengaruh terhadap arang yang dihasilkan sehingga penentuan temperatur yang tepat akan menentukan kualitas arang.

Arang tempurung adalah arang yang dibuat dengan cara karbonisasi dari tempurung atau batok kelapa. Pada proses pembakaran tempurung kelapa yang terdiri dari karbohidrat yang sangat kompleks, akan menyebabkan suatu rentetan reaksi yaitu peruraian secara termal serta menimbulkan panas sebagai hasil peruraian dari bermacam-macam struktur molekul. Pada suhu $275^{\circ} \mathrm{C}$, lingo selulosa tempurung kelapa mulai melepaskan $\mathrm{H}_{2} \mathrm{O}$ dan gas $\mathrm{CO}_{2}$, disamping itu juga terbentuk arang dan metana. (BPPI, 1983). Temperatur karbonisasi akan sangat berpengaruh terhadap arang yang

1 and 2 Jurusan Fisika Fakultas Sains dan Teknologi UIN Maulana Malik Ibrahim Malang 
dihasilkan sehingga penentuan temperatur yang tepat akan menentukan kualitas arang. (Sutiyono, 2002).

Penelitian yang mengkaji tentang formulasi dari arang kayu agar efektif dan efisien, baik dari segi ekonomis dan hasil pembakarnnya pernah di lakukan oleh Eka dan Santoso (2005), penelitian ini mengalisa pengaruh lama pembakaran terhadap nilai kalor kayu. Pada pembakaran dengan lama 15 menit dengan suhu $400 \square \mathrm{C}$ dihasilkan nilai kalor paling besar.

Penelitian yang serupa juga dilakukan oleh, Sunyata dan Wulur (2007), yang berjudul "Pengaruh Kerapatan dan Suhu Pirolisa terhadap kualitas Briket Arang Serbuk Kayu Sengon " penelitian ini variasi suhu yang diberikan hanya dua kali sehingga memungkinkan ketidakvalitan hasil data yang diperoleh.

Secara tidak langsung peneltian di atas menggambarkan bahwa nilai kalor yang dihasilkan dari arang berbeda dengan berubahnya suhu pirolisa dan perubahan nilai kalor tersebut juga dipengaruhi oleh bahan. Sehingga untuk menemukan formulasi pengarangan dengan kualitas yang baik, Maka perlu dilakukan penelitian tentang "Efek Suhu Pada Proses Pengarangan Terhadap Nilai Kalor Pada Arang Tempurung Kelapa”.

\section{KAJIAN TEORI}

Kelapa (cocos nucifera) memiliki bagian yang berfungsi sebagai pelindung inti buah yang disebut tempurung kelapa. Tempurung kelapa terletak dibagian dalam kelapa setelah sabut, dan merupakan lapisan yang keras dengan ketebalan 3-5 mm.

Tempurung kelapa temasuk golongan kayu keras, dengan kadar air sekitar Sembilan sampai sepuluh persen (dihitung berdasarkan berat kering).

Kelapa temasuk golongan kayu keras, yang secara kimiawi memiliki komposisi kimiawi hampir serupa dengan kayu yaitu tersusun dari lignin, cellulose dan hemicelluloses. Dengan komposisi yang berbeda-beda. Cellulose (C6H10O5)n 33,61 \%, Hemicellulose (C5H8O4)n 19,27\% dan lignin [(C9H10O3) (CH3O)]n 36,51\%.

Karbonisasi merupakan proses konversi dari suatu zat organic ke dalam karbon atau residu yang mengandung karbon dalam proses pembuatan arang berkarbon, karbonisasi dilakukan dengan membakar tempurung kelapa untuk menghilangkan kandungan air atau moisture content dan material - material lain dalam tempurung kelapa yang tidak di butuhkan oleh arang seperti hydrogen dan oksigen atau material yang menguap.

Menurut Koesoemadinata (1980), nilai kalor bahan bakar adalah jumlah panas yang dihasilkan atau ditimbulkan oleh suatu gram bahan bakar tersebut dengan meningkatkan temperatur 1 gr air dari 3,50 C - 4,50 C, dengan satuan kalori. Dengan kata lain nilai kalor adalah besarnya panas yang diperoleh dari pembakaran suatu jumlah tertentu bahan bakar.

Nilai kalor tergantung pada sifat bahan yang mempengaruhi massa jenisnya. Sehingga Semakin tinggi berat jenis bahan bakar, maka semakin tinggi nilai kalor yang 
diperolehnya. Nilai kalor juga akan berpengaruh pada laju pembakaran pada proses pembakaran, semakin tinggi nilai kalor bakar maka semakin lambat laju pembakaran pada proses pembakaran.

\section{METODE PENELITIAN}

Dalam melaksanakan penelitian ini digunakan suatu metode dan prosedur penelitian, sehinggga langkah-langkah serta tujuan dari penelitian yang dilakukan dapat sesuai dengan apa yang diharapkan.

\section{Waktu dan Tempat Penelitian}

Penelitian ini dilaksanakan pada bulan Desember sampai januari 2010, dilaksanakan di Workshop Elektronik Jurusan Fisika dan Labortaorium Kimia Fisis Jurusan Kimia, Fakultas Sains dan Teknologi, Universitas Islam Negeri (UIN) Maulana Malik Ibrahim Malang.

\section{Jenis Penelitian}

Jenis penelitian adalah studi eksperimental, dengan melakukan pendekatan penelitian secara kuantitatif. Adapun analisis hasil penelitian menggunakan analisi regresi untuk mengetahui hubungan nilai suhu pada pengaragan dengan nilai kalor arang tempurung kelapa.

\section{Alat dan Bahan}

Alat

Oven, Gergaji mesin, Mortal, Desikator, Neraca analitik, Furnace dan Calorimetry Bomb

Bahan

Tempurung kelapa, tempurung kelapa yang digunakan pada penelitian ini adalah tempurung kelapa hibrida yang masih segar dan umur sekitar 11 bulan.

\section{Rancangan Penelitian}

\section{A. Pembuatan Sampel}

Pembuatan sampel pada peneletian ini terdiri dari proses pengolahan bahan baku dan proses menghilangkan kadar air.

1. Pengolahan bahan

Bahan diambil dari pohon kelapa hibrida berupa buah kelapa dari pohon, buah yang diambil buah yang sudah tua dan dari ranting buah yang sama. kemudian buah kelapa dikupas dan diambil hanya bagian tempurungnya, tempurung kemudian dibersihkan dari sabut. 


\section{Pengeringan}

Proses pengeringan dilakukan untuk menghilangkan kadar air yang tekandung pada bahan, hal ini agar pada proses pengarangan, bobot bahan tidak dipengaruhi oleh kadar air. Proses pengeringan dilakukan menggunakan Oven dengan suhu pemanasan $110 \square \mathrm{C}$ selama 2 jam.

\section{B. Pengarangan (Karbonisai)}

Proses pengarangan pada penelitian ini menggunakan furnace, furnace merupakan alat pemanas seperti oven dengan suhu antara $0^{\circ} \mathrm{C}-1000^{\circ} \mathrm{C}$. sedangkan langkahlangkah yang dilakukan pada proses pengarangan adalah sebagai berikut:

1. Membungkus bahan dengan alumunium foil, agar tejadi pembakaran tidak sempurna sehingga menghasilkan residu beupa arang.

2. Tempurung dimasukkan ke dalam furnace dengan variasi suhu pemanasan, $200^{\circ} \mathrm{C}$, $250^{\circ} \mathrm{C}, 300^{\circ} \mathrm{C}, 350{ }^{\circ} \mathrm{C}, 400^{\circ} \mathrm{C}, 450^{\circ} \mathrm{C}, 500^{\circ} \mathrm{C}, 550^{\circ} \mathrm{C}$.

3. Setiap variasi suhu dipanaskan sebanyak 3 sampel untuk pengulangan.

4. Dan waktu pemanaasan diberikan selama 1,5 jam.

5. Setelah pengarangan bahan ditimbang kembali untuk mengetahui massa bahan.

6. Dan bahan ditumbuk menjadi bentuk serbuk untuk dilakukan uji kalor.

\section{Pengujian nilai kalor bakar}

Pengujian nilai kalor bakar pada penelitian ini menggunakan Kalorimeter Bom, berat bahan yang digunakan sebanyak 1 gram, adapun langkah-langkah pengujiannya adalah sebagai berikut:

1. Siapkan 2 liter air, kemudian masukkan ke dalam oval bucket.

2. Timbang 1 gram dari bahan bakar yang diuji, kemudian masukkan ke dalam combustion capsule.

3. Pasang kawat sepanjang $10 \mathrm{~cm}$ sehingga mengenai bahan bakar yang diuji tanpa mengenai permukaan besi combustion capsule dengan menggunakan bantuan bomb head support stand.

4. Masukkan 1 gram bahan bakar yang diuji dalam combustion capsule tadi bersama dengan kawat, ke dalam oxygen bomb.

5. Hubungkan semua peralatan bomb calorimeter dengan listrik.

6. Isi oxygen bomb dengan oksigen yang bertekanan 30 atm - 35 Atm menggunakan bantuan auto charger.

7. Setelah selesai, masukkan oxygen bomb ke dalam oval bucket yang telah terisi air.

8. Kemudian masukkan oval bucket ke dalam adiabatic calorimeter, lalu tutup.

9. Pindahkan posisi switch ke posisi on.

10. Sterilkan/samakan suhu dari aquades/air di oval bucket dengan suhu water jacket dengan menggunakan switch hot/cold.

11. Setelah sama, catat suhu yang terjadi.

12. Kemudian, bakar bahan bakar yang diuji tersebut. 
13. Beberapa saat kemudian, catat kembali suhu yang terjadi pada aquades/air (catat temperatur maksimum yang tercapai).

14. Alat dimatikan kemudian bomb dikeluarkan dan diukur panjang kawat yang tersisa pada bomb head support stand.

15. Setelah itu hitung selisih temperatur di air pada kondisi awal dengan kondisi setelah terjadi pembakaran.

16. Selisih tersebut kalikan dengan standard benzoid dengan tabung warna hijau .

17. Setelah itu hitung sisa kawat yang terbakar .

Dari situlah nilai kalor dari bahan bakar yang diuji diketahui.

Adapun rumusan untuk mengetahui nilai kalor menggunaka kalorimeter bomb sebagai berikut:

$$
\text { Nilai Kalor }=\frac{(\text { EE } x \Delta T)-(\text { Acid })-(\text { Fulse })}{m}
$$

Ket :

$\mathrm{EE}=$ standard benzoit $2487.780 \mathrm{Cal} / \mathrm{gram}$.

Acid $($ Sisa Abu $)=10 \mathrm{kal} /$ gram

Fulse ( panjang kawat yang terbakar $)=1 \mathrm{kal} / \mathrm{gram} / \mathrm{cm}$.

$\mathrm{m}=$ massa bahan (gram).

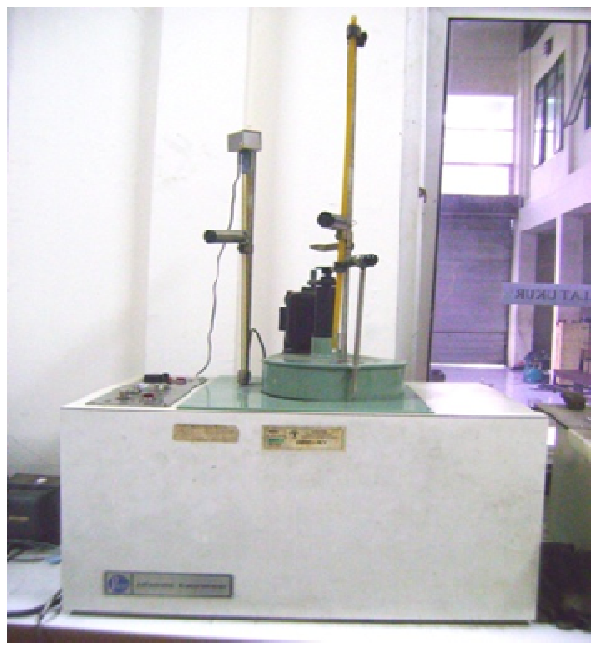

Gambar 1: Bomb Calorimeter Adiabatic

\section{Analisa Data}

Teknik analisis data dari hasil penelitian ini menggunakan dua metode analisis yaitu analisis variasi (ANOVA) dan analisis regresi. Analisis variasi digunakan untuk mengetahui perbedaan antara rata-rata nilai kalor dengan 3 pengulangan dari variasi suhu yang diberikan. Prosedur yang digunakan pada analisis variasi disini adlah oneway ANOVA. Sedangkan analisis regresi, yaitu mencari hubungan antara variable 
bebas dengan varibel terikat dalam bentuk grafik, Sehingga dapat mendiskripsikan hubungan variasi suhu pengarangan bahan terhadap nilai kalor yang terkandung pada arang tempurung kelapa.

\section{HASIL DAN PEMBAHASAN}

\section{Hasil Penelitian}

Pengaruh suhu pengarangan terhadap massa bahan

Tabel 1. Pengaruh suhu pengarangan terhadap massa bahan

\begin{tabular}{|l|l|l|l|}
\hline No & Suhu Pengarangan ( $\square \mathrm{C})$ & $\begin{array}{l}\text { Massa Sebelum } \\
\text { Pengarangan }\left({ }^{\circ} \mathrm{C}\right)\end{array}$ & $\begin{array}{l}\text { Massa Sesudah Pengarangan ( } \\
\square\end{array}$ \\
\hline 1 & 200 & 10 & 8.9 \\
\hline 2 & 250 & 10 & 7.55 \\
\hline 3 & 300 & 10 & 5.27 \\
\hline 4 & 350 & 10 & 4.00 \\
\hline 5 & 400 & 10 & 3.79 \\
\hline 6 & 450 & 10 & 3.29 \\
\hline 7 & 500 & 10 & 3.06 \\
\hline 8 & 550 & 10 & 3.06 \\
\hline
\end{tabular}

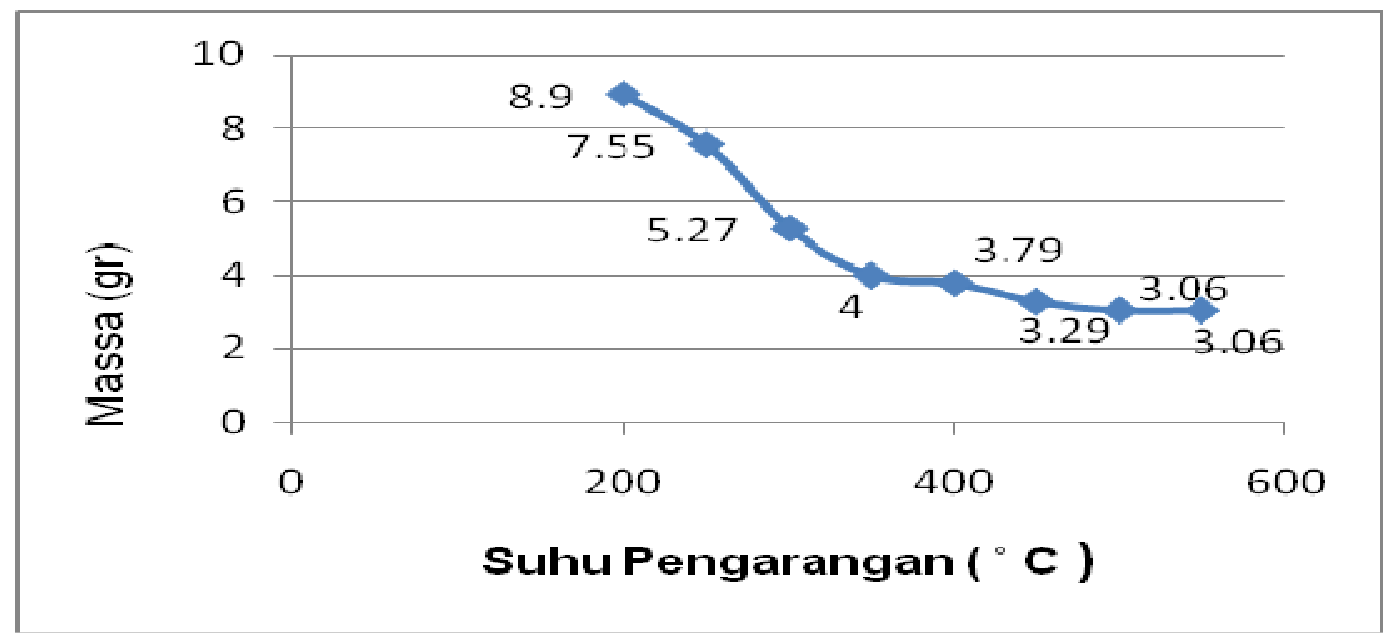

Gambar 2. Pengaruh suhu pengarangan terhadap massa bahan 
Pengaruh suhu pengarangan tehadap nilai kalor.

Tabel 2. Pengaruh suhu pengarangan tehadap nilai kalor.

\begin{tabular}{|l|c|c|}
\hline No & Suhu Karbonisasi & Nilai Kalor \\
& $\left({ }^{\circ} \mathbf{C}\right)$ & (Kal/gr) \\
\hline 1 & 200 & 5238.009 \\
\hline 2 & 250 & 5562.386 \\
\hline 3 & 300 & 6730.876 \\
\hline 4 & 350 & 6971.729 \\
\hline 5 & 400 & 7163.758 \\
\hline 6 & 450 & 7660.414 \\
\hline 7 & 500 & 7842.718 \\
\hline 8 & 550 & 8142.685 \\
\hline
\end{tabular}

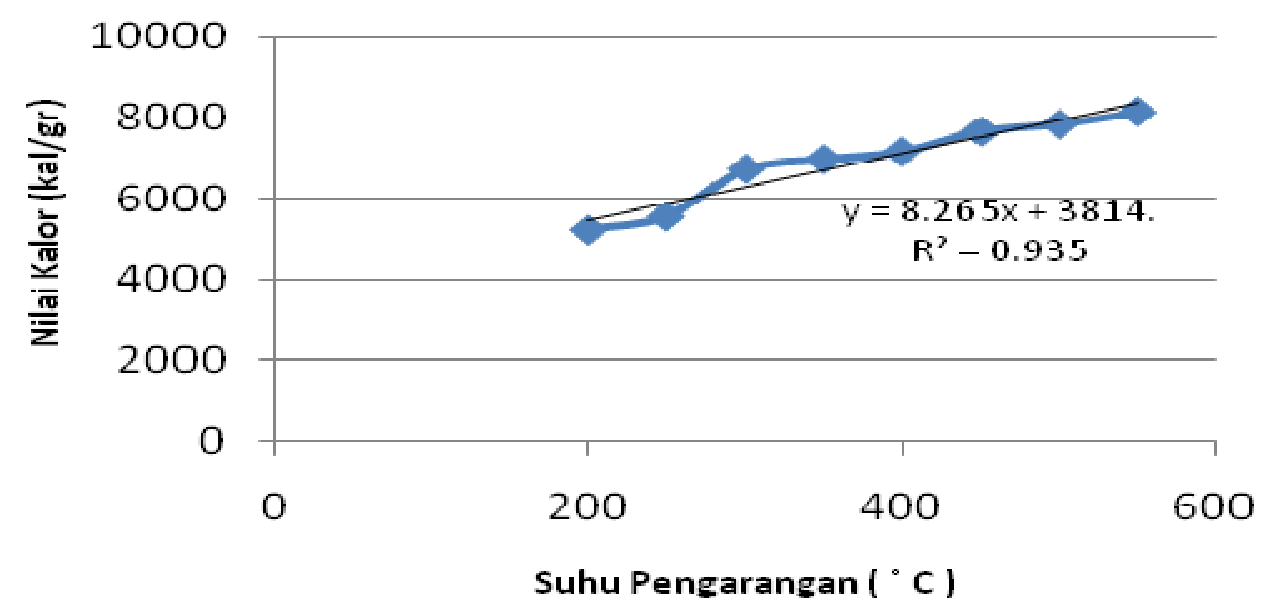

Gambar 3. Pengaruh suhu pengarangan tehadap nilai kalor.

\section{PEMBAHASAN}

\section{Pengaruh suhu pengarangan terhadap penurunan massa bahan.}

Berdasarkan Tabel 4.1 dapat diketahui bahwa massa bahan dari interval suhu 200 $-550{ }^{\circ} \mathrm{C}$ mengalami penurunan. Penurunan massa bahan paling kecil terjadi pada suhu $200{ }^{\circ} \mathrm{C}$ yaitu, dari 10 gram menjadi 8,9 gram, dan penurunan massa paling besar terjadi pada suhu $550{ }^{\circ} \mathrm{C}$ yaitu, dari 10 gram menjadi 3,06 gram.

Penurunan massa bahan disebabkan karena terjadinya pemanasan yang mengakibatkan dekomposisi bahan atau terlepasnya senyawa yang mudah menguap 
atau volatile matter. Volatile matter terdiri dari metan, senyawa hidrokarbon, hydrogen dan nitrogen. Menurut Sutiyono, (2002), pengarangan merupakan pembakaran biomassa tanpa adanya kehadiran oksigen. Sehingga yang terlepas hanya bagian volatile matter, sedangkan karbonnya tetap karena karbon tidak akan terjadi pembakaran jika tanpa oksigen (O2). Temperatur pengarangan berpengaruh terhadap arang yang dihasilkan sehingga penentuan temperatur yang tepat akan menentukan kualitas arang.

Keenan (1991), menurut teori molekul kinetik, dengan ditambahkan energi kalor ke suatu zat, energi itu digunakan untuk mengalahkan gaya-gaya tarik yang mengikat partikel-parikel. Semakin tinggi energi kalor yang diberikan maka akan semakin kuat energi untuk mengalahkan gaya-gaya tarik antar molekul. Pada komposisi tempurung kelapa, Lignin, cellulose dan hemicellulose akan mengalami dekomposisi atau pelepasan ikatan yang membentuk senyawa. Dari dekomposisi bahan tersebut akan terjadi penurunan massa bahan dengan semakin tingginya suhu pengarangan.

Pengaruh penurunan massa bahan ini secara tidak langsung meggambarkan bahwa semakin tinggi suhu pengarangan maka semakin banyak bahan yang digunakan dalam proses pengarangan. Banyaknya bahan yang digunakan mengakibatkan biaya yang dibutuhkan semakin besar dan daya listrik yang harus dikeluarkan juga semakin tinggi, oleh karena itu untuk memperoleh suhu pengarangan yang efektif dan efisien serta untuk menekan biaya yang kecil diperlukan suhu pengarangan yang lebih rendah.

\section{Pengaruh suhu pengarangan terhadap nilai kalor arang.}

Setelah proses pengarangan, bahan dijadikan serbuk untuk mempermudah proses pembakaran yang terjadi pada oxygen bomb dalam kalorimeter bom, karena semakin kecil ukuran partikel bahan semakin cepat partikel itu terbakar.

Berdasarkan data yang diperoleh, dapat dijelaskan bahwa nilai kalor semakin tinggi seiring dengan tingginya suhu pengarangan, hal ini terbukti pada suhu $200{ }^{\circ} \mathrm{C}$ menghasilkan nilai kalor paling kecil yaitu, sebesar $5238.009 \mathrm{kal}$, dan pada suhu 550 ${ }^{\circ} \mathrm{C}$ menghasilkan nilai kalor paling tinggi yaitu, sebesar $8142.685 \mathrm{kal}$.

Anonymous (2005), menyatakan bahwa pengarangan merupakan pembakaran tidak sempurna tanpa adanya oksigen, sehingga terjadi pelepasan senyawa yang mudah menguap kedalam bentuk gas atau asap dan meninggalkan residu berupa arang karbon. Karbon tidak akan terjadi pembakaran jika tanpa O2 sehingga semakin tinggi suhu pengarangan mengakibatkan semakin tinggi kadar karbon seperti tabel 3.2 pada temperatur pengarangan kayu.

Pada proses pengarangan, karbon terbentuk secara baik pada suhu antara $300^{\circ} \mathrm{C}$ $-500{ }^{\circ} \mathrm{C}$, dan akan menimbulkan asap akibat terlepasnya unsur yang mudah menguap. Cellulose dengan rumus kimia (C6H10O5)n akan terdeformasi atau akan terurai unsurunsurnya pada temperature $325-375 \square$ C. sedangkan hemicellulose dengan rumus kimia (C5H8O4)n akan terdeformasi pada suhu 225 - $325 \square$ C. dan lignin dengan rumus kimia $[(\mathrm{C} 9 \mathrm{H} 10 \mathrm{O} 3)(\mathrm{CH} 3 \mathrm{O})] \mathrm{n}$ akan terdeformasi pada suhu $300-500 \square \mathrm{C}$ (Wijaya, 2007).

Dilihat dari jumlah atom yang dimiliki oleh ketiga senyawa di atas, lignin memiliki jumlah atom karbon yang paling banyak sedangkan hemicelulose memiliki 
jumlah atom karbon paling sedikit. Jumlah atom karbon tersebut mempengaruhui kandungan karbon pada arang, sehingga bertambahnya kadar karbon berbanding lurus dengan tingginya suhu pengarangan yang mengakibatkan semakin tinggi nilai kalor arang (tabel 4.7).

Karbon merupakan atom yang mudah terbakar. Pembakaran atom karbon dapat menyebabkan tingginya energi kalor dari suatu bahan, sehingga semakin tinggi kadar karbon maka semakin tinggi nilai kalor arang.

\section{KESIMPULAN}

Berdasarkan hasil penelitian serta pembahasan yang telah dijelaskan, dapat diambil kesimpulan sebagai berikut:

1. Suhu pengarangan berpengaruh terhadap penyusutan massa tempurung kelapa, semakin tinggi suhu pengarangan maka semakin tinggi penyusutan massa tempurung kelapa.

2. Suhu pengarangan berpengaruh terhadap nilai kalor arang tempurung kelapa, semakin tinggi suhu pengarangan maka semakin tinggi nilai kalor arang tempurung kelpa.

\section{DAFTAR PUSTAKA}

Anonymous, (2005). Carbonisation Processes. (n.d.).. http://www.fao.org/docrep/ X5328E/x5328e0e.htm\#TopOfPage. Tanggal akses 21 November, 2010. Abdullah. 2004. Tafsir Ibnu Katsir Jilid 8. Bogor: Pustaka Imam Asy-Syafi'i.

Borman, G.L., dan Ragland, K.W. (1998). Combustion Engineering, McGraw-Hill Book Co., Singapore.

BKPMD Sulteng, 2008, Studi Kelayakan Arang Tempurung Kelapa, Profil Proyek Badan Koordinasi Penanaman Modal Daerah: Sulaweai Tengah.

BPPI, 1983, Pembuatan Karbon Aktif dan Tempurung Inti Sawit, Departemen Perindustrian: Jakarta.

IDirektorat Gizi Departemen Kesehatan RI. 1981. Daftar Komposisi Bahan Makanan. Bhatara Karya Aksara: Jakarta.

Hasbullah, 2001, Teknologi Tepat Guna Agroindustri Kecil Sumatera Barat, Dewan Ilmu Pengetahuan Teknologi dan Industri: Sumatera Barat. 
Jati, Eka. 2005. Penetuan Kalor Bakar Arang Dari Dari Sejumlah Jenis Kayu Dan Lama Pirolisis. Jurnal Fisika Indonesia. Jurusan Fisika FMIPA Universitas Gadja Mada Yogyakarta

Kleinfelter, Wood. 1989. Kimia Untuk Universitas Jilid I. Jakarta : Erlangga.

Suyitno, 2002, Pembuatan Briket Arang Dari Tempurung Kelapa Dengan Bahan Pengikat Tetes Tebu Dan Tapioka, Jurnal Kimia dan Teknologi: Surabaya.

Sugiyono. 2007. Statistik untuk Penelitian. Alfabeta: Jakarta

Tjokrowisasto, Eddy Harmadi \& Widodo, Budi Utomo Kukuh (1990). Teknik Pembakaran Dasar dan Bahan Bakar. Jurusan Teknik Mesin, Fakultas Teknologi Industri, ITS: Surabaya.

Turns, Stephen R. 2000. An Introduction Of Combustion: Concepts and Aplications $\left(2^{\text {nd }}\right.$ ed.). Singapure: McGraw-Hill.

Wijaya, Hendra. 2007. Perencenaan Drum Klin Untuk Karbonisasi Arang Tempurung Kelapa. Skripsi Jurusan Teknik Mesin Fakultas Fakultas Teknologi Industri: Universitas Kristen Petra.

Zemansky, Mark W dan Richard H. Dittman. 1986. Kalor dan Termodinamika, ITB: Bandung. 